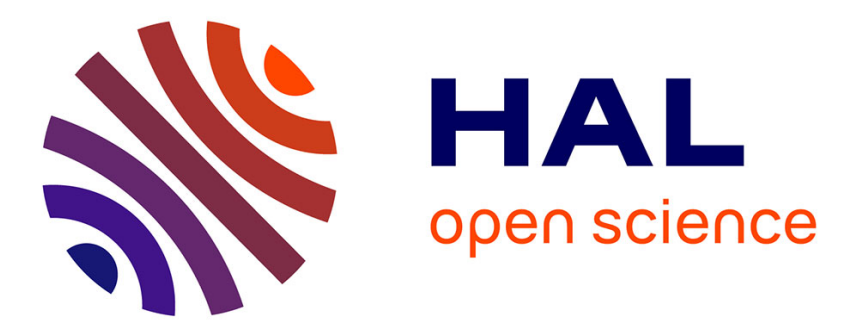

\title{
Methylation of class I translation termination factors: Structural and functional aspects
}

Marc Graille, Sabine Figaro, Stéphanie Kervestin, Richard H Buckingham, Dominique Liger, Valérie Heurgué-Hamard

\section{To cite this version:}

Marc Graille, Sabine Figaro, Stéphanie Kervestin, Richard H Buckingham, Dominique Liger, et al.. Methylation of class I translation termination factors: Structural and functional aspects. Biochimie, 2012, 94 (7), pp.1533 - 1543. 10.1016/j.biochi.2012.01.005 . hal-03298514

\section{HAL Id: hal-03298514 https://hal.science/hal-03298514}

Submitted on 26 Jul 2021

HAL is a multi-disciplinary open access archive for the deposit and dissemination of scientific research documents, whether they are published or not. The documents may come from teaching and research institutions in France or abroad, or from public or private research centers.
L'archive ouverte pluridisciplinaire HAL, est destinée au dépôt et à la diffusion de documents scientifiques de niveau recherche, publiés ou non, émanant des établissements d'enseignement et de recherche français ou étrangers, des laboratoires publics ou privés. 
Methylation of class I translation termination factors: structural and functional aspects

Marc Graille $^{1 *}$, Sabine Figaro ${ }^{2}$, Stéphanie Kervestin², Richard H. Buckingham², Dominique Liger $^{1}$ and Valérie Heurgué-Hamard ${ }^{2 *}$.

${ }^{1}$ IBBMC, Université Paris-Sud 11, CNRS UMR8619, Orsay Cedex, F-91405, France

2 CNRS, UPR 9073 associated with Université Paris Diderot, Sorbonne Paris Cité, IBPC, 13 rue Pierre et Marie Curie, Paris, F-75005, France.

To whom correspondence should be addressed:

Dr Marc Graille

IBBMC, Building 430, University Paris-Sud

91405 Orsay Cedex

France

Email : marc.graille@u-psud.fr

Tel : 331 69.15.31.57 / Fax : 33169.85 .37 .15

Dr Valérie Heurgué-Hamard

13, rue Pierre \& Marie Curie

75005 Paris

France

Email : valerie.heurgue@ibpc.fr

Tel : 33 1 58.41.51.45 / Fax : 33 1 58.41.50.20 


\begin{abstract}
During protein synthesis, release of polypeptide from the ribosome occurs when an in frame termination codon is encountered. Contrary to sense codons, which are decoded by tRNAs, stop codons present in the A-site are recognized by proteins named class I release factors, leading to the release of newly synthesized proteins. Structures of these factors bound to termination ribosomal complexes have recently been obtained, and lead to a better understanding of stop codon recognition and its coordination with peptidyl-tRNA hydrolysis in bacteria. Release factors contain a universally conserved GGQ motif which interacts with the peptidyl-transferase centre to allow peptide release. The Gln side chain from this motif is methylated, a feature conserved from bacteria to man, suggesting an important biological role. However, methylation is catalysed by completely unrelated enzymes. The function of this motif and its post-translational modification will be discussed in the context of recent structural and functional studies.
\end{abstract}

\title{
149 words.
}

\section{Highlights}

- The recognition of stop codon by release factors (RFs) induces peptide release.

- The universally conserved GGQ motif from RFs is methylated from bacteria to man.

- Trm112 activates several methyltransferases acting on translation components.

\section{Keywords}

Translation termination / Post-translational modification / Methyltransferases. 


\section{Introduction}

The termination step of translation allows the release of newly synthesized proteins, in response to the presence of a stop codon in mRNA. In all kingdoms of life, the stop codon is recognized by class I release factors (RFs), which bind to the ribosomal A-site and promote hydrolysis of peptidyl-tRNA in the peptidyl-transferase centre (PTC). These proteins are assisted in their function by class II RFs, but in a different way in prokaryotes and eukaryotes [1].

Despite a similar function, prokaryotic and eukaryotic/archaeal RFs are radically different in primary and tertiary structures, with the exception of an essential and universally conserved tripeptide motif Gly-Gly-Gln (GGQ) located at one tip of the molecule and interacting with the ribosomal peptidyl transferase centre [2-4]. In both bacteria and eukarya, this motif is post-translationally modified by methylation, one of the most common modifications after phosphorylation. The Gln side chain of this motif is converted into $\mathrm{N}^{5}$ methyl-glutamine by specific protein methyltransferases (MTases): PrmC in E. coli or the Mtq2-Trm112 complex in S. cerevisiae [5, 6].

Translation termination requires a perfect coordination between two events on different ribosomal sites, i.e. recognition of the stop codon in the decoding centre, and when this is achieved, hydrolysis of the ester bond of peptidyl-tRNA in the PTC. Different domains from class I RFs are involved in this process, as for tRNAs, leading to the notion of tRNA mimicry $[7,8]$. In recent years, many structural data have helped us to understand these mechanisms: structures of RFs alone by X-ray crystallography or in solution by Small-Angle X-ray Scattering (SAXS) [3, 4, 9], followed by cryoelectron microscopy structures of RFs bound to the ribosome $[10,11]$, and more recently higher resolution crystal structures of these complexes (for reviews, see [2, 12]).

This review summarizes recent findings regarding the mechanism of translation termination and the role and mechanism of RF methylation. In particular, we discuss identification of the enzymes mediating this modification, their physiological roles and structural mechanisms of action.

\section{General principles of translation termination mechanism}

\subsection{Function and structure of class I RFs}

\subsubsection{Bacterial Release Factors.}


In bacteria, two class I RFs detect the three stop codons with overlapping specificity: RF1 recognizes UAG and UAA while RF2 recognizes UAA and UGA stop codons. These proteins share significant sequence identity (for instance, RF1 and RF2 from E. coli display $40 \%$ sequence identity and 56\% homology) and adopt very similar three-dimensional structures $[4,13,14]$. These proteins encompass four domains (from I to IV), among which domains II and IV are associated to form a superdomain (Fig. 1A). Domain II is involved in stop codon recognition in the ribosomal decoding centre (DC) and has long been proposed to contain conserved triplets that act as "anticodon" loops. The recent high resolution structures of ribosomal complexes with the different stop codons and either RF1 or RF2, unravelled the molecular basis of stop codon recognition and revealed that the "anticodon" loop model for stop codon recognition was too simplistic (for more details on stop codon discrimination mechanisms, see recent reviews $[2,15])$. Domain III harbours within a loop the universally conserved GGQ motif, which is involved in peptidyl-tRNA hydrolysis in the PTC.

Surprisingly, all the crystal structures of isolated bacterial class I RFs $[4,13,14]$ exhibit a "closed" conformation with the two regions predicted to interact simultaneously with the ribosomal DC and PTC distant by only 20-25 (Fig. 1A), too short to span the corresponding distance in the ribosome ( $75 \AA$ ). Thus, these crystal structures do not reflect the conformation adopted by these proteins once bound to the ribosomal A-site. SAXS studies on isolated release factors [9] together with cryo-EM [10, 11], followed by crystal structures of RF1 and RF2 bound to the ribosome [16-20], confirmed that class I RFs adopt an "open" conformation compatible with their role in both stop codon recognition and catalysis of peptidy-tRNA hydrolysis (Fig. 1B).

\subsubsection{Eukaryotic release factors.}

Contrary to prokaryotes, in eukaryotes the three stop codons are recognized by a single protein [21]. This class I RF, eRF1, is composed of three domains, with no structural similarity with those of RF1 and RF2 (Fig. 1C; [3]). The N-terminal and central domains functionally correspond to domains II and III from bacterial RFs, respectively. Several distinct regions from the eRF1 N-terminal domain are involved in stop codon recognition in the DC [22]. The central domain harbours the universally conserved GGQ motif [23]. Finally, the central and C-terminal domains are implicated in the interaction with the class II RF, eRF3, a 
GTPase crucial for correct translation termination [24-26]. Since the shape of eRF1 observed in the crystal structure resembles a tRNA, it was supposed to mimic functionally the tRNA: the region centred on the conserved NIKS motif in the eRF1 N-terminal domain corresponds to the tRNA anticodon loop and the GGQ motif from the central domain corresponds to the amino-acyl acceptor stem $[7,8]$. In this structure, the distance between the NIKS motif from the N-terminal domain and the GGQ motif is slightly longer than the distance between the DC and the PTC in the eukaryotic ribosome [27], suggesting that further conformational change will be needed for optimal eRF1 function. It was subsequently proposed that eRF1 adopts its functional conformation upon binding to the eukaryotic class II RF, eRF3 [28].

\subsection{Class II translation RFs}

During translation termination, class I RFs are assisted by class II factors, RF3 in prokaryotes and eRF3 in eukaryotes. These two proteins belong to the translational GTPase family but have different roles. The bacterial RF3 promotes dissociation of RF1/RF2 from the ribosome following peptide release by stabilizing the ribosome in a ratcheted conformation incompatible with the binding of RF1/RF2 to the A-site [29-33]. Its GTPase activity is dependent on the ribosome and is stimulated by RF1/RF2 although structural modelling from crystal and cryo EM structures suggests that the class I and class II proteins do not interact together either in solution or bound to the ribosome $[30,32,33]$.

In eukaryotes, eRF1 interacts with the class II RF eRF3, a translational GTPase related to elongation factors EF-Tu and eEF-1A, in the absence of the ribosome $[26,34]$. The complex is more stable in the presence of GTP, and eRF3 binds more tightly GTP (but not GDP), in the presence of eRF1 [35-37]. The eRF1 and eRF3 proteins interact mainly through their C-terminal domains as determined both by biochemical and structural data $[28,38,39]$. However, several lines of evidence suggest that the eRF1 central domain harbouring the universally conserved GGQ motif also interacts with the eRF3 GTPase domain. First, the central domain from human eRF1 interacts directly with eRF3 in vitro [40]. Second, the central and C-terminal domains from eRF1 are necessary for eRF3 to bind GTP [40]. Third, the recent crystal structure of the Dom34-Hbs1 complex (two proteins related to eRF1 and eRF3, respectively $[41,42]$ ) has revealed that the Dom34 central domain, which is structurally similar to the corresponding domain from eRF1, interacts with the Hbs1 GTPase 
domain [43]. Structural modelling of the eRF1-eRF3-GTP complex based on the structure of the Dom34-Hbs1 complex further indicates that the distance between the eRF1 GGQ motif and the region involved in stop codon recognition nicely fits with the distance observed in the crystal structure of the eukaryotic 80S ribosome [27].

The current model regarding eRF1-eRF3 induced peptide release proposes that following binding of the eRF1-eRF3-GTP complex to pre-termination complexes, the eRF3 bound GTP molecule is hydrolysed in a ribosome- and eRF1-dependent manner [44, 45]. This would lead to rearrangement of the eRF1 central domain, which contacts the eRF3 GTPase domain in the GTP-bound form, for perfect stop codon recognition and fit into the ribosomal PTC to induce peptide release, followed by eRF3 release from the ribosome. eRF1 would remain associated with the post-termination complex and interact with the newly identified eukaryotic ribosome recycling factor Rli1/ABCE1, a conserved and essential protein of the ATP-binding cassette family [46]. This latter would then promote eRF1 dissociation from ribosomes as well as subunit dissociation $[47,48]$. Release of tRNA and mRNA from recycled 40S subunits is then mediated by eIF3, eIF1 and eIF1A [47].

\subsection{Translation termination in archaea}

Searches for orthologues of both bacterial and eukaryotic class I RFs within archaeal genomes revealed the presence of a protein related to eukaryotic eRF1 [49]. The recent crystal structure of the archaeal class I RF (aRF1) from A. pernix confirmed that aRF1 is the archaeal class I RF [50]. In parallel, the elongation factor aEF-1A has also been shown to act as the archaeal class II RF as well as in RNA quality control [50]. Finally, an ortholog of Rli1/ $\mathrm{ABCE} 1$, involved in ribosome recycling, is also present in archaea [51]. Altogether, this indicates that translation termination mechanisms are closely similar in archaea and eukaryotes.

\section{Post-translational methylation of RFs}

3.1. Structural and functional characterization of prokaryotic RF methylation

\subsubsection{Bringing to light methylation of prokaryotic $R F$}

RF2 was suspected of being modified because its specific activity and its affinity for ribosomes was lower when overproduced [52,53]. Dincbas-Renqvist et al confirmed this 
hypothesis and demonstrated that RF1 was also methylated [54]. In parallel, they showed that E. coli K12 strains expressed a peculiar and less efficient RF2 with a Thr instead of an Ala at position 246. Mass spectrometry analysis confirmed the presence of $\mathrm{N}^{5}$-methylglutamine on the conserved catalytic GGQ motif of RF1 and RF2.

Although methylation is a frequently observed modification in the translational apparatus (ribosomal proteins, tRNA, rRNA) for example, Gln side chain modification is an unusual one, so far only described for E. coli ribosomal protein L3 [55]. After identification of the enzyme methylating L3 protein (YfcB or PrmB), Heurgué-Hamard et al showed that a unique candidate, HemK (thereafter renamed PrmC) had a significant sequence similarity to this enzyme [5]. The corresponding gene was located immediately downstream of $\operatorname{prf} A$, encoding RF1 at 27 min on the genome. In vitro methylation assays performed on RF1/RF2 with purified PrmC enzyme confirmed the role of the protein in this process.

An independent study from another group who previously assigned a different function to HemK (see below) also pointed out its role in RF1/RF2 methylation [56]. Their studies were initiated by the observation that hemK was localized in the same operon as $\operatorname{prf} A$, and that the HemK sequence was related to a SAM-dependent methyltransferase (MTase) family. hemK is a striking example of genome misannotation. A genetic screen for heme biosynthetic enzymes first led to the conclusion that this gene encoded a subunit of protoporphyrinogen oxidase catalyzing one step towards heme biosynthesis (hence its name) [57]. From these data, many homologous proteins in different genomes have been designated as a "protoporphyrinogen oxidase". When further biochemical data excluded this function and showed the enzyme to be a MTase, the presence of the conserved motif NPPY in HemK homologues, previously thought to be specific to DNA adenine Mtases, then lead to a further misannotation as a nucleic acid MTase. To avoid more confusion, HemK was renamed PrmC (see Table 1 for nomenclature).

prmC is present among the proposed minimal set of genes required for life, suggesting an important role in other organisms [58]. Indeed, methylation of class I RF by a PrmC homolog was also characterized in Chlamydia trachomatis, an obligate intracellular bacterial pathogen with a small genome, phylogenetically very distantly related to E. coli [59]. In $E$. coli, prfA and prm C belong to the same operon, and the initiation codon for prmC overlaps with the termination codon of $\operatorname{prf}$. Yang et al showed that this organization was conserved in 
79 out of 126 analysed bacterial genomes [60]. However, at least in two cases, the phylogeny of the PrmC protein was different from that of RF1 and RF2, which is correlated to $16 \mathrm{~S}$ rRNA, suggesting that horizontal transfer of the prmC gene had occurred [60].

\subsubsection{Substrate recognition by PrmC methyltransferase}

The SAM-dependent PrmC MTase is composed of two domains: an N-terminal $\alpha-$ helical domain connected by a small $\beta$-hairpin to the C-terminal class I MTase domain, with a Rossman-fold consisting of a mixed $\alpha / \beta$ fold composed of a central seven stranded $\beta$-sheet surrounded by $3 \alpha$-helices on each side (Fig. 2A; [60, 61]).

The molecular basis for the recognition and methylation of bacterial class I RFs has been clarified by the crystal structure of the complex between the PrmC MTase and RF1 from E. coli [62]. In this complex, the RF1 protein adopts the "closed" conformation already observed in the crystal structures of bacterial RF1 and RF2 proteins (Fig. 2B). As expected, the PrmC MTase domain interacts with the RF1 domain III harbouring the GGQ motif while the PrmC N-terminal domain contacts both domains II and III from RF1. This latter interaction is only possible if the RF1 protein adopts the "closed" conformation, suggesting that this RF1/RF2 conformation otherwise observed only in the crystal structures of isolated proteins has biological significance rather than being a crystal artefact. To test this hypothesis, residues from the PrmC N-terminal domain involved in the RF1-PrmC interaction only if $\mathrm{RF} 1 / \mathrm{RF} 2$ is in a "closed" form, have been subjected to mutagenesis. These mutants proved to have a significantly decreased in vitro RF1/RF2 methylation activity and a reduced affinity for RF1 [62]. Altogether, these results argue that the RF1/RF2 "closed" conformation is the PrmC substrate and hence is biologically relevant.

This first structure of a complex between a MTase and its intact substrate protein has also revealed the molecular basis for RF1/RF2 recognition [62]. In particular, this structure has rationalized the functional importance of the strictly conserved ${ }^{183}{ }^{N P P Y}{ }^{186}$ motif (E. coli PrmC numbers are used for clarity), a hallmark of RF MTases and MTases modifying planar nitrogen atoms [63]. This signature is responsible for the binding and correct orientation of the Gln side chain from the ${ }^{233} \mathrm{GGQ}^{235}$ motif within the active site (E. coli $\mathrm{RF} 1$ numbers are used for clarity). The carbonyl groups from the $\mathrm{Asn}^{183}$ side chain and from the Pro ${ }^{184}$ main chain of this motif are hydrogen bonded to the Gln 235 amide group that will be methylated 
(Fig. 2C). The hydroxyl group from the Tyr ${ }^{186}$ side chain in the NPPY motif is hydrogen bonded to the main chain amide group of Gln 235 and the Tyr aromatic ring is stacked against the Gln side chain. Another hydrogen bond formed between the PrmC Arg92 side chain and the RF1 Gln²35 main chain carbonyl group is also observed. All these interactions occur between conserved residues both from PrmC and RF1/RF2 and participate in a network of interactions that ideally positions the Gln side chain for subsequent methyl transfer from the SAM cofactor bound to PrmC.

\subsubsection{Role of the GGQ motif and its methylation in peptide release}

As proposed by several studies [23, 64-67], the crystal structures of 70S termination complexes have confirmed that the GGQ motif enters the PTC [16-18, 20, 68]. The two Gly residues from this motif are sandwiched between A2602 and U2585 (Fig. 2D). These residues adopt conformations that would be energetically unfavourable for any of the 19 other natural amino acids, and bring the Gln near the A76 nucleotide at the CCA-end of the P-site tRNA. The Gln side chain points away from the scissile peptidyl-tRNA ester bond in a pocket formed by the ribose moiety of the P-site tRNA A76 as well as A2451, C2452 and U2506 from the $23 \mathrm{~S}$ rRNA (E. coli numbering used) and as a consequence, is very unlikely to contribute directly to catalysis (Fig. 2D). This correlates well with the mutational analysis showing that most substitutions of the Gln side chain by various residues (including the bulky Trp) only partially affect the catalysis of peptidyl-tRNA hydrolysis in vitro, both in bacteria and eukaryotes $[65,66,69]$. The Gln side chain could contribute indirectly and partially to catalysis by participating in the coordination of the nucleophilic water molecule. In the $3.1 \AA$ electron density maps of the 70S termination complex obtained with RF2 and a P-site tRNA substrate analog [68], the carbonyl group from this Gln side chain is located $4.2 \AA$ away from a water molecule, which could correspond to the nucleophilic water (Fig. 2D). Surprisingly, the crystal structures of $70 \mathrm{~S}$ termination complexes revealed that the main chain amide group of the Gln residue is well positioned to form a hydrogen bond with an oxygen of the tetrahedral transition state intermediate during the hydrolysis reaction and to stabilize it. To support this observation, the replacement of Gln by Pro, which prevents the formation of this hydrogen bond (but could also perturb the backbone of the loop harbouring the GGQ motif), completely abolishes RF1-mediated peptide release activity [16]. 
Comparison of all the structures of bacterial RFs bound to ribosomes reveals that the Gln side chain adopts a large variety of conformations within the PTC. This flexibility could reflect a loose packing of the Gln side chain in the PTC following peptide release, as all structures but one [68] have been obtained with a deacylated tRNA in the P-site, and hence can be considered as post-release structures. However, it could also result from loose packing of the Gln into the PTC due to the lack of methylation. Indeed, a hydrophobic pocket is located close to the Gln side-chain amide group and the methyl group could fill this hydrophobic cavity and trap this Gln side chain in an optimal orientation within the PTC. Furthermore, molecular dynamics calculation suggests that the absence of the methyl group to the Gln side chain increases the mobility of this side chain in the PTC [67]. It has been shown that the catalytic efficiency in the termination reaction and the affinity for ribosomes of the methylated bacterial RF2 in vitro are five-fold and three-fold higher, respectively, than for the unmethylated factor $[52,54]$. Similarly, methylation has been estimated to result in a five-fold increase in the efficiency of termination in vivo [64].

\subsubsection{Physiological role of $R F$ methylation}

Physiological studies of RF methylation in bacteria have been performed only in $E$. coli. In gram-positive bacteria, data from systematic gene inactivation show that $y w k E$, encoding the PrmC homolog, is not an essential gene and is not required for normal growth in rich or minimal media [70].

The biological role of translation factor methylation is not always clear and depletion of MTases usually does not cause major phenotypes [71]. In the case of RFs, prmC deletion in $E$. coli affects growth, but a distinction must be made depending on whether the strain is K12 or not. The first experiments on the role of PrmC in E. coli were done in a K12 background, where the efficiency of termination is already affected due to the $\operatorname{prf} B$ gene encoding a peculiar RF2 with a Thr at position 246 (RF2T246), shown to be less efficient in vitro and in vivo $[54,64,72]$. Other strains such as E. coli $\mathrm{B}$ and $\mathrm{C}$ or other E. coli isolates have an Ala at position 246 in RF2, and all other bacterial species carry an Ala or Ser at the corresponding position.

In K12 strains, inactivation of prm C leads to very poor growth on rich medium. A similar phenotype is observed when RF2(T246) is over-expressed. In both cases, E. coli 
produces an unmethylated and particularly defective RF2(T246) which is unable to sustain normal cell growth. Suppressors abrogating growth defects of $\mathrm{K} 12$ strains with a prmC knockout were found to carry mutations in the $p r f B$ gene, encoding RF2T246A or RF2T246S $[5,56]$. The cumulative termination defects described in K12 strains in the absence of RF methylation are reminiscent of recent data showing also that $\mathrm{K} 12$ growth is also largely compromised in the presence of a mutation in the $r l u D$ gene, decreasing RF2 activity [73, 74]. This gene encodes a pseudouridine synthase modifying three positions of helix 69 of $23 \mathrm{~S}$ rRNA critical for RF activity [75]. In both cases, the decreased rate of termination has been shown to induce transfer-mRNA (tmRNA)-mediated tagging of proteins $[56,74]$.

prm C inactivation also affected the growth of E. coli B strains expressing RF2(A246) on minimal media, especially with poor carbon sources like succinate or acetate. It was suggested that the decreased specific activity of RF1 and RF2(A246) due to their lack of methylation impaired synthesis of proteins required to grow on minimal media [64]. In conclusion, we propose that RF methylation is more specifically required under suboptimal conditions, for growth on minimal media or when specific pathways must be active under stress conditions. In the same vein, it is interesting to note that, for reasons to be determined, Yersinia pseudotuberculosis $\operatorname{PrmC}(\mathrm{VagH})$ is required for virulence in a mouse infection model, although not for growth in rich liquid media. However, as in B strains of E. coli, a vagH mutant grew more slowly in a less nutrient rich defined medium [76].

\subsection{Eukaryotic RF methylation}

\subsubsection{Characterization of eRF methylation and identification of the enzyme involved}

The perfect conservation of the GGQ motif in RFs from all kingdoms together with the widespread presence of genes encoding potential PrmC homologues in metazoa led to the question as to whether eRF1 was also modified in S. cerevisiae. Yeast cytoplasmic eRF1 was found to be methylated in vivo on the Gln of its GGQ motif by two independent studies [77, 78]. S. cerevisiae genome analysis revealed two genes encoding proteins with significant homology to E. coli PrmC, containing a SAM binding site and a conserved NPPY motif involved in methylation catalysis: Mtq1 (YNL063w) and Mtq2 (YDR140w). Mtq1 is localized in mitochondria and methylates in vivo the conserved GGQ motif from mitochondrial RF1 (mRF1), which has high sequence similarity to bacterial RF1 [78]. As in 
the case of $E$. coli $\mathrm{RF} 1 / \mathrm{RF} 2$ and PrmC, modification of $\mathrm{mRF} 1$ can be reproduced in vitro by adding purified Mtq1 and SAM, showing that Mtq1 is sufficient for catalysis [78]. Methylation of human mitochondrial RF HMRF1L, catalyzed by the HMPrmC enzyme, was also described [79]. Using in vivo and in vitro approaches, the Mtq2 enzyme was shown to be essential for cytoplasmic eRF1 methylation $[77,78]$.

Several observations made during the characterization of Mtq2 suggested that it was not acting alone. Only impure preparations of Mtq2 produced from yeast were active in methylation, and with low efficiency [77]. Moreover, expression of Mtq2 alone in E. coli led to insoluble protein, which remained inactive after classical solubilization/renaturation protocols $[6,77]$. Large scale interactome studies, using the two hybrid system or tandem affinity purification followed by mass spectrometry, identified several proteins potentially interacting with Mtq2 $[80,81]$. Among them, Trm112 was a candidate, potentially interacting also with tRNA MTases Trm9 and Trm11. These interactions were later confirmed through biochemical analysis and shown to be essential for tRNA methylation [82-84]. Adding Trm112 to purified Mtq2 from inclusion bodies allowed methylation of eRF1 in vitro in the presence of eRF3 (eRF3Ct was used for in vitro experiments) and showed that these proteins formed an enzymatically active complex able to methylate eRF1 in vitro [6]. Yeast eRF1 methylation is distinct from E. coli RF methylation in two respects: (1) to be methylated, eRF1 needs to be part of a ternary complex together with eRF3-GTP, consistent with the fact that these proteins readily form a heterodimer in vivo; (2) eRF1 MTase is a complex of two subunits: Mtq2 which carries the catalytic activity and the zinc finger protein Trm112 [6]. Trm112 is conserved in eukaryotes, together with its interaction with several MTases. In vitro studies showed that methylation of human and murine eRF1 are performed respectively by HemK2 $\alpha / \mathrm{hTrm} 112$ and PRED28 $\alpha / \mathrm{mTrm} 112$, and required the presence of eRF3 and GTP [85]. Analysis by mass spectrometry also showed that methylation is present in endogenous human eRF1 and is dependent of the predicted MTase catalytic subunit [86]. However, only $70 \%$ of endogenous human eRF1 is methylated in cultured HEK-293T cells. Complete methylation is observed only after ectopic expression of the MTase. Finally, the expression of human HemK $2 \alpha$ can complement the growth defect of yeast strains deleted for $m t q 2$, suggesting that it is able to interact in vivo with yeast Trm112 as observed in vitro [85]. 


\subsubsection{Structure of the Mtq2-Trm 112 methyltransferase}

Bioinformatics analysis has revealed the existence of proteins with sequence homology to yeast Trm112 within the three kingdoms of life, with molecular weights ranging from $6 \mathrm{kDa}$ in bacteria and archae to around $15 \mathrm{kDa}$ in eukaryotes. Regions with significant homology are clustered near the amino-terminus (30 residues) and the carboxy terminus (25-35 residues), while a central region composed of 60-70 residues is only found in eukaryotes. Interestingly, a well-conserved $\mathrm{CX}_{3} \mathrm{C}$ motif $\left(\mathrm{CX}_{2} \mathrm{C}\right.$ in archaea and prokaryotes $)$ is observed in the $\mathrm{N}$-terminal region together with a $\mathrm{CX}_{2} \mathrm{C}$ motif in the $\mathrm{C}$-terminal part, suggesting the presence of a zinc-binding site within most Trm112 proteins, and confirmed by the crystal structure of S. cerevisiae Trm112 [6]. The four cysteine residues from S. cerevisiae Trm112 bind a zinc atom and residues 1-40 as well as 103-135 fold together as a zinc knuckle domain. In S. cerevisiae Trm112, the central region specific for eukaryotic Trm112 proteins folds as a helical domain formed by $3 \alpha$-helices.

The crystal structure of the Mtq2-Trm112 complex from the small eukaryotic parasite Encephalitozoon cuniculi shows that Trm112 interacts mainly via its zinc knuckle domain with Mtq2, suggesting that this complex also forms in archaea where orthologues of both proteins are present (Fig. 3A; [87]). Mtq2 protein is structurally very similar to the MTase domain from bacterial PrmC, although the PrmC N-terminal helical domain and the linker connecting this domain to the MTase domain appear to be absent from Mtq2 [77]. The structure further reveals that Trm112 is not a structural stand-in for these missing regions since it is located on the side of the Mtq2 active site whereas the PrmC N-terminal domains and the linker are located at the top of the PrmC active site, in the orientation seen in Fig. 2A and 3A. Even though PrmC and Mtq2-Trm112 modify the same motif in class I RFs, is the differences are not surprising as the bacterial and eukaryotic RFs are unrelated at the levels of both amino acid sequence and three-dimensional structure.

The structure of the Mtq2-Trm112 complex reveals that large hydrophobic regions located at the surface of both proteins interact upon complex formation, explaining the enhancement of yeast Mtq2 solubility by Trm112 [6]. Trm112 mutants located at the heterodimeric interface abolish Mtq2 enzymatic activity, no doubt by disrupting complex formation [87]. The structure has also brought important clues about the molecular basis for Mtq2 activation by Trm112. This cannot solely be due to solubilisation, as small amounts of 
human Mtq2 could be purified in a soluble form, appeared well folded by circular dichroism (MG and VHH unpublished data), but proved to be inactive in the absence of Trm112 [85]. Instead, in the structure, Trm112 interacts with a loop from Mtq2, which in turn contacts the SAM cofactor, suggesting that Trm112 enhances the interaction of Mtq2 with this essential cofactor of the MTase reaction. This was confirmed using the human proteins: Mtq2 alone binds SAM very weakly while Mtq2 incubated with Trm112 or the co-expressed Trm112Mtq2 complex bind a significantly larger fraction of SAM [87]. Furthermore, SAM binding to Trm9, another MTase activated by Trm112, stabilizes the Trm112-Trm9 complex and probably other complexes formed by Trm112 with MTases.

The Mtq2 active site has been mapped to a highly conserved region surrounding the SAM methyl group. Comparison of the Mtq2-Trm112 structure with the bacterial PrmC-RF1 complex confirms that this region corresponds to the PrmC MTase region which interacts with the loop in PrmC harbouring the GGQ motif. In particular, the (D/N)PPY active site signature, identified as a hallmark of MTases modifying planar amine groups, i.e. N6-adenine [88], N4-cytosine [89] or the N5-Gln side chain [61], superimposes perfectly between bacterial and eukaryotic RF MTases (Fig. 3B). As discussed above, in bacteria this motif is responsible for the binding and correct orientation of the Gln side chain from the GGQ motif in the PrmC active site [62]. Hence, we propose that the same network of interaction as in bacteria is used by Mtq2 to optimally orient the Gln side chain amino group for methyl transfer. In addition, this conserved region is rich in negatively charged residues, as in the bacterial PrmC enzyme. Charge inversion mutants of these acidic residues have shown that this region is important for eRF1 methylation [87]. This is of particular interest as in a model of the yeast eRF1-eRF3-GTP complex inferred from the archaeal Dom34-Hbs1-GTP complex [43], the eRF1 central domain is locked in interaction with the eRF3 GTPase domain and its GGQ motif is surrounded by several conserved Lys and Arg residues. Some of these basic residues are located along the long helix $\alpha 5$ from the eRF1 central domain. Mutation of most of these eRF1 residues does not disrupt interaction with eRF3 but results in complete loss of methylation by Mtq2-Trm112, suggesting their implication in enzyme binding (VHH and MG, unpublished data). In addition, in the eRF1-eRF3-GTP model, the GGQ motif is located near helix $\alpha 4$ of the eRF3 switch I loop, which is enriched in strictly conserved basic residues on its solvent-exposed face. We cannot exclude that these residues interact directly with the 
Mtq2-Trm112 active site. Altogether, these observations might rationalize the requirement of eRF3 bound to GTP for eRF1 methylation [77]. First, when bound to eRF3-GTP, the eRF1 central domain might be stabilized and the GGQ motif could then adopt an optimal orientation for entry into the MTase active site. Second, as the switch regions from GTPases are known to adopt radically different conformations depending on the nucleotide bound (GTP or GDP; [90]), the GTP nucleotide may induce a conformation of eRF3 switch I (helix $\alpha 4)$ that allows the basic residues from helix $\alpha 4$ to interact directly with Mtq2-Trm112. On the contrary, following eRF1-induced and ribosome-induced GTP hydrolysis, this loop may adopt a completely different structure, incompatible with enzyme binding.

Finally, mutation of solvent-exposed Trm112 residues affect partially the Mtq2 MTase activity without disrupting either Mtq2-Trm112 complex formation or the protein fold (as observed by circular dichroism). This indicates that Trm112 may also be partially involved in direct substrate recognition by the Mtq2-Trm112 complex. Interestingly, the Mtq2-Trm112 complex displays striking structural similarity to RlmA proteins, MTases catalyzing the N1methylation of guanine at position G745 (Gram-negative bacteria) or G748 (Gram-negative bacteria) of 23S rRNA [91, 92]. RlmA proteins contain a zinc-binding domain, which was proposed to be involved in substrate recognition and which structurally matches the Trm112 zinc-binding domain [91].

\subsubsection{Physiological role of eukaryotic RF methyltransferases}

Inactivation of yeast MTQ1 encoding mitochondrial RF (Mrf1) MTase slightly decreases growth only on liquid media containing a non-fermentable carbon source; this is an indicator of its mitochondrial function. As in bacteria, this deletion also affects translation termination in mitochondria, increasing readthrough at a premature stop codon in the mitochondrial COX2 gene [78]. However, it remains to be established if reduced growth on glycerol is due to inefficient translation termination of essential proteins under these conditions. Depletion of human mitochondrial MTase in HeLa cells leads to a small decrease in mitochondrial translation activity but this phenotype is amplified in the presence of the translation fidelity antibiotic spectinomycin [79]. This observation is reminiscent of the prokaryotic system where PrmC appears to become essential only under certain poor growth conditions or under some stress. 
Deletion of the yeast $M T Q 2$ gene encoding the catalytic subunit of the cytoplasmic eRF1 MTase has more far reaching consequences and multiple phenotypes. The $m t q 2 \Delta$ strain is viable but exhibits strong growth defects with a twofold longer generation time on rich media and a cold-sensitive phenotype $[77,78]$. It is also sensitive to aminoglycosides like paromomycin and geneticin, which are known to affect translation fidelity through binding to ribosomes (VHH and SF, unpublished data; [78]). The $m t q 2 \Delta$ mutant also presents other striking phenotypes such as resistance to the anti-microtubule drugs thiabendazole and benomyl [78]. Clearly, these phenotypes incite many questions and cannot easily be linked to eRF1 methylation defects, raising the possibility of another substrate for Mtq2.

Contrary to the situation in bacteria or yeast mitochondria, the absence of eRF1 methylation in a yeast $m t q 2 \Delta$ strain does not significantly decrease the efficiency of translation termination. MTQ2 deletion does not increase translational readthrough in vivo and may even have the opposite effect ([78]; VHH, SF unpublished data). Hence, the growth defect of a $m t q 2 \Delta$ strain may be unrelated to termination. In agreement with this, it has been shown that increased stop codon readthrough in eRF1 mutants, tpal 1 , ett $1 \Delta$ strains or $\left[\mathrm{PSI}^{+}\right]$ variants does not lead to a reduction in growth rate [93-96]. Since the PTC as well as other functionally crucial regions of ribosomes are extremely well conserved between bacteria and eukaryotes, a conclusion confirmed by the recent high-resolution structure of the yeast ribosome, this result was quite unexpected [27]. This might result from the differences in translation mechanisms between prokaryotes and eukaryotes. So far, the efficiency of translation termination in eukaryotes has only been measured in vivo, where other proteins might compensate for the absence of methylation. Alternatively, the termination step could also be so efficient that a decrease might not be detectable in some assays.

Some studies of the murine Mtq2 ortholog (mN6amt1 or PRED28, according to the nomenclature) were performed on the assumption that it was a N6-DNA MTase, prior to its identification as an $\mathrm{N}^{5}$-Gln-MTase [97]. Two mRNAs resulting from alternative splicing and encoding proteins related to murine RF MTase were identified. The Pred $28 \alpha$ and Pred $28 \beta$ mRNAs encode respectively for a $23 \mathrm{kDa}$ protein homologous to Mtq2, and a putative one of 14.7 $\mathrm{kDa}$ resulting from exon $\mathrm{V}$ splicing. Both mRNAs were detected in mouse brain and testis,among other tissues. The longer isoform is very abundant in stem cells and adult tissues. Surprisingly, two different studies on cell cultures after plasmid transfection localized the 
GFP-tagged proteins mainly in the nucleus. The smaller form, predicted to be unstable as a large portion of the structural core is absent, was also observed in the nucleus in a stable transfected cell line. Whether this form is also present in natural cell lines is not known. In human, two mRNA species resulting from alternative splicing of exon IV have also been described [97]. If produced in the cell, the shorter protein would not contain the NPPY essential motif for catalysis, and would be inactive in methylation.

Depletion of Pred28 $\alpha$ by RNA interference in murine embryonic stem cells leads to a defect in cell proliferation with an arrest in G1 phase [98]. Similarly, HEK293T human cells in culture with a stable knock down of HemK2 have a two-fold reduction in growth rate [86]. Finally, homozygous mice with disruption of Pred28 $\alpha$ (replacement of exon IV encoding the NPPY motif) are characterized by early embryonic lethality impairing the post-implantation development of mutant embryos. This phenotype is extreme, compared to $S$. cerevisiae where the gene is not essential under standard conditions and growth is only reduced under particular stress conditions.

\section{Trm112 interacts with several methyltransferases involved in translation}

An increasing number of proteins interacting with and activating enzymes has been described in recent years. For example, the catalytically active conformation of histone acetyltransferase Rtt109 is stabilised by Vps75 [99]. Several MTases exist as holoenzymes, such as the tRNA modification enzymes Trm8-Trm82 [100] and Trm6-Trm61 [101], and the capping MTase enzymes from vaccinia virus and man [102, 103].

The Trm112 protein is particularly interesting since it interacts with and activates three MTases (Mtq2, Trm11 and Trm9) acting on macromolecules involved in translation (Fig.3C). S. cerevisiae Trm11 and its archaeal orthologue PAB1283 from P. abyssi methylate the guanosine at position 10 in tRNAs to generate $\mathrm{m}^{2} \mathrm{G} 10$, a modification assumed to be involved in tRNA stability $[83,104]$. Trm9 catalyzes the last step of a long series of reactions needed to generate 5-methoxycarbonylmethyl-uridine $\left(\mathrm{mcm}^{5} \mathrm{U}_{34}\right)$ at the wobble position of the anticodon loop in some tRNAs (tRNA ${ }^{A r g}$, tRNA $^{\text {Glu }}, \ldots$ ) in yeast, plants and mammals $[82$, 105-108]. This Trm9-Trm112 catalyzed modification is very likely to be involved in decoding fidelity, and experimental evidence suggests that this modification is involved in the cellular response to genotoxic stresses in yeast $[109,110]$. Indeed, codons recognized by tRNAs 
modified by the Trm9-Trm112 complex are over-represented in genes encoding proteins involved in the response to DNA damage, such as RNR1 and RNR3.

Several lines of evidence support the idea that these three MTases compete to interact with Trm112: (i) the catalytic domains of these proteins are predicted to belong to the class Idependent MTase family and to adopt the same three-dimensional fold; (ii) coimmunoprecipitation assays indicate that over-expression of Trm11 or Mtq 2 affects the interaction of Trm9 with Trm112 [84]; (iii) over-expression of Trm11 or Mtq2 results in Trm9 inactivation illustrated by the increased resistance of budding yeast to zymocin (a killer toxin cleaving only those tRNAs that have been fully modified at position U34 by various enzymes including Trm9; [84, 111]); (iv) Trm9 mutants constructed on the basis of a model of the Trm9-Trm112 complex derived from the Mtq2-Trm112 structure and aimed at disrupting the interaction with Trm112, are catalytically inactive and unable to interact with Trm112 in vivo [87]. Finally, the interaction of Trm 112 with Mtq2 would be fully compatible for Trm 112 binding to the other 3 MTases. In the Mtq2-Trm112 complex, the two partners interact via a $\beta$-zipper interaction involving hydrogen bonds between main chain atoms from Trm112 strand $\beta 4$ and Mtq 2 strand $\beta 3$ [87]. This mode of interaction is therefore less sensitive to variation of side chains at the positions involved and is well adapted to interaction with proteins of divergent sequence but similar folds. For instance, it is also used by bacterial proteins interacting with the antigen binding fragment $(\mathrm{Fab})$ region of a large panel of antibodies and B-cell receptors $[112,113]$. Global quantitative analysis of these proteins in yeast indicates that under normal growth conditions, the 3 MTases together are more abundant than Trm112, indicating that not all molecules may be saturated with Trm112 [114].

Most studies regarding the physiological role of Trm112 have been performed in $S$. cerevisiae. Due to the extremely reduced growth of trm $112 \Delta$ cells, trm 112 is still annotated as an essential gene in the Saccharomyces Genome Database. However, recent measurements indicate a generation time of about 6 hours for trm112 $\Delta$ compared to 1.5 hours for a wild type strain in rich liquid medium ([82]; SF and VHH, unpublished data). The trm $112 \Delta$ strain is even more affected than a strain deleted for all genes encoding MTase partners of Trm112 (Mtq2, Trm9, Trm11), suggesting that Trm112 has additional functions in yeast. However, the absence of Mtq2 activity contributes to a large part to this phenotype ([82, 115], SF and VHH, unpublished data). Other potential partners of Trm112 suggested by large scale 
interactome studies include Ecm16 and Sfh1, and a reduced function of these proteins may also contribute to the dramatic reduction in growth of trm112 $\Delta$.

Trm112 orthologs exist in eukaryotic and archaeal kingdoms, and some interactions with eRF1 or tRNA MTase orthologs are also conserved $[85,105,108]$. For instance, Arabidopsis thaliana protein SMO2 is a functional analog of yeast Trm112 since its expression in S. cerevisiae restores cell growth [116]. As in S. cerevisiae, the inactivation of SMO2 leads to a defect in cell growth. SMO2 is also required for proper cell division and development, but the mechanisms underlying this phenotype are still unknown.

\section{Conclusions}

With the progress of proteomics methods such as mass spectrometry and purification of endogenous proteins, it has becoming increasingly evident that post-translational modifications are widely present in all living organisms. These events are known to expand protein sequence complexity and to play crucial roles in various cellular processes and their regulation. Studies concerning the role of these chemical modifications are very much in their infancy, and their impact has yet to be determined. In most cases, it is difficult to predict posttranslational modifications only from protein sequence, and identification of the enzyme involved is not always an easy task.

Methylation is one of the most common modifications found on proteins and nucleic acids, although many other targets have been identified. SAM-dependent MTases can be classified in several groups according to their structural folding, the major group adopting the class I, Rossman-like fold. Their identification in complete genomes is difficult because their primary sequence similarity is very low.

N5-methylation of Gln side chains is an unusual modification, so far found only in ribosomal protein L3 in E. coli and related bacteria, and class 1 RFs in bacteria and eukaryotes. Here we review the mechanism of RF methylation and the role of this modification, present on the Gln of the universally conserved and essential GGQ motif. In bacteria, RF methylation clearly stimulates RF function. In eukaryotes, RF methylation is more complex, and the role uncertain. The MTase turned out to be a heterodimerc complex formed by the Mtq2 catalytic subunit and its Trm112 partner. Though Mtq2 was predicted some time ago from S. cerevisiae complete genome analysis to be a MTase, much 
experimental work was needed to identify its substrate and mechanism of action. Further studies are still necessary to understand more precisely the role of RF modification, particularly in eukaryotic organisms. Some observations suggest that the Mtq2 MTase has other substrates than eRF1, as yet unidentified. Several other questions are still open: what are the reasons for the essential role of the mammalian MTase? Are the two polypeptides resulting from translation of alternatively spliced mRNA really produced? If so, what are their respective roles? If methylation of eRF1 is also incomplete in cells from a complete organism, does that imply a regulatory mechanism and a more complex biological significance? In addition, HemK 2 is encoded on human chromosome 21 and may have a role in the pathology of Down syndrome. Whether or not this pathology is correlated to a deficiency in eRF1 methylation remains to be determined. In C. elegans, a HemK2 ortholog has been identified and has been shown to be localized specifically in some parts of the nervous system from the larval stage until adulthood.

$\operatorname{Trm} 112$ is necessary for proper folding of Mtq 2 and its activation by improving SAM binding. Surprisingly, Trm112 is more than a simple activator of the Mtq2 MTase, and can now be considered as an activating platform, insofar as it activates in a similar manner two tRNA MTases. Trm112 is a "hub" protein central to protein synthesis mechanisms, and more studies will be needed to fully decipher its interactions and physiological functions.

\section{Acknowledgements}

We thank Pr H. van Tilbeurgh for his continuous support. We are indebted to L. Mora, N. Lazar, J. Cicolari, N. Ulryck, N. Scrima, S. Champ for technical assistance and to Dr. J. Henri for his involvement in this project. This work was supported by the Agence Nationale pour la Recherche (grants ANR-06-BLAN-0075-02 and ANR-07-JCJC-0105); the Centre National pour la Recherche Scientifique; the University Paris-Sud, the Human Frontier Science Program organism (grant RGP0018/2009-C) and the EU '3D-Repertoire' program (LSHGCT-2005-512028). We apologize to those authors whose work we have not been able to cite due to space restraints.

\section{References}

[1] P.G. Loh, Song H., Structural and mechanistic insights into translation termination, Curr Opin Struct Biol 20 (2010) 98-103. 
[2] B.P. Klaholz, Molecular recognition and catalysis in translation termination complexes, Trends Biochem Sci 36 (2011) 282-292.

[3] H. Song, Mugnier P., Das A.K., Webb H.M., Evans D.R., Tuite M.F., Hemmings B.A., Barford D., The crystal structure of human eukaryotic release factor eRF1--mechanism of stop codon recognition and peptidyl-tRNA hydrolysis, Cell 100 (2000) 311-321.

[4] B. Vestergaard, Van L.B., Andersen G.R., Nyborg J., Buckingham R.H., Kjeldgaard M., Bacterial polypeptide release factor RF2 is structurally distinct from eukaryotic eRF1, Mol Cell 8 (2001) 1375-1382.

[5] V. Heurgué-Hamard, Champ S., Engstöm Å., Ehrenberg M., Buckingham R.H., The hemK gene in Escherichia coli encodes the N(5)-glutamine methyltransferase that modifies peptide release factors, EMBO J. 21 (2002) 769-778.

[6] V. Heurgue-Hamard, Graille M., Scrima N., Ulryck N., Champ S., van Tilbeurgh H., Buckingham R.H., The zinc finger protein Ynr046w is plurifunctional and a component of the eRF1 methyltransferase in yeast, J Biol Chem 281 (2006) 36140-36148.

[7] L.L. Kisselev, Buckingham R.H., Translational termination comes of age, Trends Biochem Sci 25 (2000) 561-566.

[8] Y. Nakamura, Ito K., Ehrenberg M., Mimicry grasps reality in translation termination, Cell 101 (2000) 349-352.

[9] B. Vestergaard, Sanyal S., Roessle M., Mora L., Buckingham R.H., Kastrup J.S., Gajhede M., Svergun D.I., Ehrenberg M., The SAXS solution structure of RF1 differs from its crystal structure and is similar to its ribosome bound cryo-EM structure, Mol Cell 20 (2005) 929-938.

[10] B.P. Klaholz, Pape T., Zavialov A.V., Myasnikov A.G., Orlova E.V., Vestergaard B., Ehrenberg M., van Heel M., Structure of the Escherichia coli ribosomal termination complex with release factor 2, Nature 421 (2003) 90-94.

[11] U.B. Rawat, Zavialov A.V., Sengupta J., Valle M., Grassucci R.A., Linde J., Vestergaard B., Ehrenberg M., Frank J., A cryo-electron microscopic study of ribosome-bound termination factor RF2, Nature 421 (2003) 87-90.

[12] A.A. Korostelev, Structural aspects of translation termination on the ribosome, RNA 17 (2011) 1409-1421.

[13] D.H. Shin, Brandsen J., Jancarik J., Yokota H., Kim R., Kim S.H., Structural analyses of peptide release factor 1 from Thermotoga maritima reveal domain flexibility required for its interaction with the ribosome, J Mol Biol 341 (2004) 227-239.

[14] G. Zoldak, Redecke L., Svergun D.I., Konarev P.V., Voertler C.S., Dobbek H., Sedlak E., Sprinzl M., Release factors 2 from Escherichia coli and Thermus thermophilus: structural, spectroscopic and microcalorimetric studies, Nucleic Acids Res 35 (2007) 1343-1353.

[15] Y. Nakamura, Ito K., tRNA mimicry in translation termination and beyond, Wiley Interdiscip Rev RNA 2 (2011) 647-668.

[16] A. Korostelev, Asahara H., Lancaster L., Laurberg M., Hirschi A., Zhu J., Trakhanov S., Scott W.G., Noller H.F., Crystal structure of a translation termination complex formed with release factor RF2, Proc Natl Acad Sci U S A 105 (2008) 19684-19689.

[17] A. Korostelev, Zhu J., Asahara H., Noller H.F., Recognition of the amber UAG stop codon by release factor RF1, EMBO J 29 (2010) 2577-2585.

[18] M. Laurberg, Asahara H., Korostelev A., Zhu J., Trakhanov S., Noller H.F., Structural basis for translation termination on the 70S ribosome, Nature 454 (2008) 852-857.

[19] S. Petry, Brodersen D.E., Murphy F.V.t., Dunham C.M., Selmer M., Tarry M.J., Kelley A.C., Ramakrishnan V., Crystal structures of the ribosome in complex with release factors RF1 and RF2 bound to a cognate stop codon, Cell 123 (2005) 1255-1266. 
[20] A. Weixlbaumer, Jin H., Neubauer C., Voorhees R.M., Petry S., Kelley A.C., Ramakrishnan V., Insights into translational termination from the structure of RF2 bound to the ribosome, Science 322 (2008) 953-956.

[21] L. Frolova, Le Goff X., Rasmussen H.H., Cheperegin S., Drugeon G., Kress M., Arman I., Haenni A.L., Celis J.E., Philippe M., et al., A highly conserved eukaryotic protein family possessing properties of polypeptide chain release factor, Nature 372 (1994) 701-703.

[22] L. Frolova, Seit-Nebi A., Kisselev L., Highly conserved NIKS tetrapeptide is functionally essential in eukaryotic translation termination factor eRF1, RNA 8 (2002) 129-136.

[23] L.Y. Frolova, Tsivkovskii R.Y., Sivolobova G.F., Oparina N.Y., Serpinsky O.I., Blinov V.M., Tatkov S.I., Kisselev L.L., Mutations in the highly conserved GGQ motif of class 1 polypeptide release factors abolish ability of human eRF1 to trigger peptidyl-tRNA hydrolysis, RNA 5 (1999) 1014-1020.

[24] L. Frolova, Le Goff X., Zhouravleva G., Davydova E., Philippe M., Kisselev L., Eukaryotic polypeptide chain release factor eRF3 is an eRF1- and ribosome-dependent guanosine triphosphatase, RNA 2 (1996) 334-341.

[25] J. Salas-Marco, Bedwell D.M., GTP hydrolysis by eRF3 facilitates stop codon decoding during eukaryotic translation termination, Mol Cell Biol 24 (2004) 7769-7778. [26] G. Zhouravleva, Frolova L., Le Goff X., Le Guellec R., Inge-Vechtomov S., Kisselev L., Philippe M., Termination of translation in eukaryotes is governed by two interacting polypeptide chain release factors, eRF1 and eRF3, Embo J 14 (1995) 4065-4072. [27] A. Ben-Shem, Jenner L., Yusupova G., Yusupov M., Crystal structure of the eukaryotic ribosome, Science 330 (2010) 1203-1209.

[28] Z. Cheng, Saito K., Pisarev A.V., Wada M., Pisareva V.P., Pestova T.V., Gajda M., Round A., Kong C., Lim M., Nakamura Y., Svergun D.I., Ito K., Song H., Structural insights into eRF3 and stop codon recognition by eRF1, Genes Dev 23 (2009) 1106-1118. [29] D.V. Freistroffer, Pavlov M.Y., MacDougall J., Buckingham R.H., Ehrenberg M., Release factor RF3 in E.coli accelerates the dissociation of release factors RF1 and RF2 from the ribosome in a GTP-dependent manner, EMBO J 16 (1997) 4126-4133.

[30] H. Gao, Zhou Z., Rawat U., Huang C., Bouakaz L., Wang C., Cheng Z., Liu Y., Zavialov A., Gursky R., Sanyal S., Ehrenberg M., Frank J., Song H., RF3 induces ribosomal conformational changes responsible for dissociation of class I release factors, Cell 129 (2007) 929-941.

[31] G. Grentzmann, Kelly P.J., Laalami S., Shuda M., Firpo M.A., Cenatiempo Y., Kaji A., Release factor RF-3 GTPase activity acts in disassembly of the ribosome termination complex, RNA 4 (1998) 973-983.

[32] H. Jin, Kelley A.C., Ramakrishnan V., Crystal structure of the hybrid state of ribosome in complex with the guanosine triphosphatase release factor 3, Proc Natl Acad Sci U S A 108 (2011) 15798-15803.

[33] J. Zhou, Lancaster L., Trakhanov S., Noller H.F., Crystal structure of release factor RF3 trapped in the GTP state on a rotated conformation of the ribosome, RNA (2011).

[34] I. Stansfield, Jones K.M., Kushnirov V.V., Dagkesamanskaya A.R., Poznyakovski A.I., Paushkin S.V., Nierras C.R., Cox B.S., Ter-Avanesyan M.D., Tuite M.F., The products of the SUP45 (eRF1) and SUP35 genes interact to mediate translation termination in Saccharomyces cerevisiae, EMBO J 14 (1995) 4365-4373.

[35] V. Hauryliuk, Zavialov A., Kisselev L., Ehrenberg M., Class-1 release factor eRF1 promotes GTP binding by class-2 release factor eRF3, Biochimie 88 (2006) 747-757.

[36] V.A. Mitkevich, Kononenko A.V., Petrushanko I.Y., Yanvarev D.V., Makarov A.A., Kisselev L.L., Termination of translation in eukaryotes is mediated by the quaternary 
eRF1*eRF3*GTP*Mg2+ complex. The biological roles of eRF3 and prokaryotic RF3 are profoundly distinct, Nucleic Acids Res 34 (2006) 3947-3954.

[37] V.P. Pisareva, Pisarev A.V., Hellen C.U., Rodnina M.V., Pestova T.V., Kinetic analysis of interaction of eukaryotic release factor 3 with guanine nucleotides, J Biol Chem 281 (2006) 40224-40235.

[38] K. Ebihara, Nakamura Y., C-terminal interaction of translational release factors eRF1 and eRF3 of fission yeast: G-domain uncoupled binding and the role of conserved amino acids, RNA 5 (1999) 739-750.

[39] T.I. Merkulova, Frolova L.Y., Lazar M., Camonis J., Kisselev L.L., C-terminal domains of human translation termination factors eRF1 and eRF3 mediate their in vivo interaction, FEBS Lett 443 (1999) 41-47.

[40] A.V. Kononenko, Mitkevich V.A., Dubovaya V.I., Kolosov P.M., Makarov A.A., Kisselev L.L., Role of the individual domains of translation termination factor eRF1 in GTP binding to eRF3, Proteins 70 (2008) 388-393.

[41] M. Graille, Chaillet M., van Tilbeurgh H., Structure of yeast Dom34: a protein related to translation termination factor Erf1 and involved in No-Go decay, J Biol Chem 283 (2008) 7145-7154.

[42] A.M. van den Elzen, Henri J., Lazar N., Gas M.E., Durand D., Lacroute F., Nicaise M., van Tilbeurgh H., Seraphin B., Graille M., Dissection of Dom34-Hbs1 reveals independent functions in two RNA quality control pathways, Nat Struct Mol Biol 17 (2010) 1446-1452.

[43] K. Kobayashi, Kikuno I., Kuroha K., Saito K., Ito K., Ishitani R., Inada T., Nureki O., Structural basis for mRNA surveillance by archaeal Pelota and GTP-bound EF1alpha complex, Proc Natl Acad Sci U S A 107 (2010) 17575-17579.

[44] E.Z. Alkalaeva, Pisarev A.V., Frolova L.Y., Kisselev L.L., Pestova T.V., In vitro reconstitution of eukaryotic translation reveals cooperativity between release factors eRF1 and eRF3, Cell 125 (2006) 1125-1136.

[45] L.Y. Frolova, Merkulova T.I., Kisselev L.L., Translation termination in eukaryotes: polypeptide release factor eRF1 is composed of functionally and structurally distinct domains, RNA 6 (2000) 381-390.

[46] S. Khoshnevis, Gross T., Rotte C., Baierlein C., Ficner R., Krebber H., The ironsulphur protein RNase L inhibitor functions in translation termination, EMBO Rep 11 (2010) 214-219.

[47] A.V. Pisarev, Skabkin M.A., Pisareva V.P., Skabkina O.V., Rakotondrafara A.M., Hentze M.W., Hellen C.U., Pestova T.V., The role of ABCE1 in eukaryotic posttermination ribosomal recycling, Mol Cell 37 (2010) 196-210.

[48] C.J. Shoemaker, Green R., Kinetic analysis reveals the ordered coupling of translation termination and ribosome recycling in yeast, Proc Natl Acad Sci U S A 108 (2011) E1392-1398.

[49] P.P. Dennis, Ancient ciphers: translation in Archaea, Cell 89 (1997) 1007-1010.

[50] K. Saito, Kobayashi K., Wada M., Kikuno I., Takusagawa A., Mochizuki M., Uchiumi T., Ishitani R., Nureki O., Ito K., Omnipotent role of archaeal elongation factor 1 alpha (EF1alpha) in translational elongation and termination, and quality control of protein synthesis, Proc Natl Acad Sci U S A 107 (2010) 19242-19247.

[51] D. Barthelme, Dinkelaker S., Albers S.V., Londei P., Ermler U., Tampe R., Ribosome recycling depends on a mechanistic link between the FeS cluster domain and a conformational switch of the twin-ATPase ABCE1, Proc Natl Acad Sci U S A 108 (2011) 3228-3233. 
[52] M.Y. Pavlov, Freistroffer D.V., Dincbas V., MacDougall J., Buckingham R.H., Ehrenberg M., A direct estimation of the context effect on the efficiency of termination, J Mol Biol 284 (1998) 579-590.

[53] W.P. Tate, Adamski F.M., Brown C.M., Dalphin M.E., Gray J.P., Horsfield J.A., McCaughan K.K., Moffat J.G., Powell R.J., Timms K.M., Trotman C.N.A., Translational stop signal: evolution, decoding for protein synthesis and recoding for alternative events, in: K.H. Nierhaus, Franceshi F., Subramanian A.R., Erdmann V.A. and Wittmann-Liebold B. (Eds.), The translational apparatus: Structure, fonction, regulation, evolution, Plenum Press, New-York, 1993, pp. 253-261.

[54] V. Dincbas-Renqvist, Engstrom A., Mora L., Heurgue-Hamard V., Buckingham R., Ehrenberg M., A post-translational modification in the GGQ motif of RF2 from Escherichia coli stimulates termination of translation, Embo J 19 (2000) 6900-6907. [55] C. Colson, Lhoest J., Urlings C., Genetics of ribosomal protein methylation in Escherichia coli. III. Map position of two genes, $\mathrm{prmA}$ and $\mathrm{prmB}$, governing methylation of proteins L11 and L3, Molec. Gen. Genet. 169 (1979) 245-250.

[56] K. Nakahigashi, Kubo N., Narita S., Shimaoka T., Goto S., Oshima T., Mori H., Maeda M., Wada C., Inokuchi H., HemK, a class of protein methyl transferase with similarity to DNA methyl transferases, methylates polypeptide chain release factors, and hemK knockout induces defects in translational termination, Proc Natl Acad Sci U S A 99 (2002) 1473-1478.

[57] T. Nakayashiki, Nishimura K., Inokuchi H., Cloning and sequencing of a previously unidentified gene that is involved in the biosynthesis of heme in Escherichia coli, Gene 153 (1995) 67-70.

[58] E.V. Koonin, Mushegian A.R., Rudd K.E., Sequencing and analysis of bacterial genomes, Curr Biol 6 (1996) 404-416.

[59] Y. Pannekoek, Heurgue-Hamard V., Langerak A.A., Speijer D., Buckingham R.H., van der Ende A., The N5-glutamine S-adenosyl-L-methionine-dependent methyltransferase PrmC/HemK in Chlamydia trachomatis methylates class 1 release factors, J Bacteriol 187 (2005) 507-511.

[60] Z. Yang, Shipman L., Zhang M., Anton B.P., Roberts R.J., Cheng X., Structural characterization and comparative phylogenetic analysis of Escherichia coli HemK, a protein (N5)-glutamine methyltransferase, J Mol Biol 340 (2004) 695-706.

[61] H.L. Schubert, Phillips J.D., Hill C.P., Structures along the catalytic pathway of PrmC/HemK, an N5-glutamine AdoMet-dependent methyltransferase, Biochemistry 42 (2003) 5592-5599.

[62] M. Graille, Heurgue-Hamard V., Champ S., Mora L., Scrima N., Ulryck N., van Tilbeurgh H., Buckingham R.H., Molecular basis for bacterial class I release factor methylation by PrmC, Mol Cell 20 (2005) 917-927.

[63] H.L. Schubert, Blumenthal R.M., Cheng X., Many paths to methyltransfer: a chronicle of convergence, Trends Biochem Sci 28 (2003) 329-335.

[64] L. Mora, Heurgue-Hamard V., de Zamaroczy M., Kervestin S., Buckingham R.H., Methylation of bacterial release factors RF1 and RF2 is required for normal translation termination in vivo, J Biol Chem 282 (2007) 35638-35645.

[65] A. Seit-Nebi, Frolova L., Justesen J., Kisselev L., Class-1 translation termination factors: invariant GGQ minidomain is essential for release activity and ribosome binding but not for stop codon recognition, Nucleic Acids Res 29 (2001) 3982-3987.

[66] J.J. Shaw, Green R., Two distinct components of release factor function uncovered by nucleophile partitioning analysis, Mol Cell 28 (2007) 458-467. 
[67] S. Trobro, Aqvist J., A model for how ribosomal release factors induce peptidyltRNA cleavage in termination of protein synthesis, Mol Cell 27 (2007) 758-766.

[68] H. Jin, Kelley A.C., Loakes D., Ramakrishnan V., Structure of the 70 S ribosome bound to release factor 2 and a substrate analog provides insights into catalysis of peptide release, Proc Natl Acad Sci U S A 107 (2010) 8593-8598.

[69] E.M. Youngman, McDonald M.E., Green R., Peptide release on the ribosome: mechanism and implications for translational control, Annu Rev Microbiol 62 (2008) 353-373.

[70] K. Kobayashi, Ehrlich S.D., Albertini A., Amati G., Andersen K.K., Arnaud M., Asai K., Ashikaga S., Aymerich S., Bessieres P., Boland F., Brignell S.C., Bron S., Bunai K., Chapuis J., Christiansen L.C., Danchin A., Debarbouille M., Dervyn E., Deuerling E., Devine K., Devine S.K., Dreesen O., Errington J., Fillinger S., Foster S.J., Fujita Y., Galizzi A., Gardan R., Eschevins C., Fukushima T., Haga K., Harwood C.R., Hecker M., Hosoya D., Hullo M.F., Kakeshita H., Karamata D., Kasahara Y., Kawamura F., Koga K., Koski P., Kuwana R., Imamura D., Ishimaru M., Ishikawa S., Ishio I., Le Coq D., Masson A., Mauel C., Meima R., Mellado R.P., Moir A., Moriya S., Nagakawa E., Nanamiya H., Nakai S., Nygaard P., Ogura M., Ohanan T., O'Reilly M., O'Rourke M., Pragai Z., Pooley H.M., Rapoport G., Rawlins J.P., Rivas L.A., Rivolta C., Sadaie A., Sadaie Y., Sarvas M., Sato T., Saxild H.H., Scanlan E., Schumann W., Seegers J.F., Sekiguchi J., Sekowska A., Seror S.J., Simon M., Stragier P., Studer R., Takamatsu H., Tanaka T., Takeuchi M., Thomaides H.B., Vagner V., van Dijl J.M., Watabe K., Wipat A., Yamamoto H., Yamamoto M., Yamamoto Y., Yamane K., Yata K., Yoshida K., Yoshikawa H., Zuber U., Ogasawara N., Essential Bacillus subtilis genes, Proc Natl Acad Sci U S A 100 (2003) 4678-4683.

[71] B. Polevoda, Sherman F., Methylation of proteins involved in translation, Mol Microbiol 65 (2007) 590-606.

[72] M. Uno, Ito K., Nakamura Y., Functional specificity of amino acid at position 246 in the tRNA mimicry domain of bacterial release factor 2, Biochimie 78 (1996) 935-943.

[73] M. Dreyfus, Heurgue-Hamard V., Termination troubles in Escherichia coli K12, Mol Microbiol 79 (2011) 288-291.

[74] R.E. Schaub, Hayes C.S., Deletion of the RluD pseudouridine synthase promotes SsrA peptide tagging of ribosomal protein S7, Mol Microbiol 79 (2010) 331-341.

[75] M. Ejby, Sorensen M.A., Pedersen S., Pseudouridylation of helix 69 of 23S rRNA is necessary for an effective translation termination, Proc Natl Acad Sci U S A 104 (2007) 19410-19415.

[76] S. Garbom, Forsberg A., Wolf-Watz H., Kihlberg B.M., Identification of novel virulence-associated genes via genome analysis of hypothetical genes, Infect Immun 72 (2004) 1333-1340.

[77] V. Heurgue-Hamard, Champ S., Mora L., Merkulova-Rainon T., Kisselev L.L., Buckingham R.H., The glutamine residue of the conserved GGQ motif in Saccharomyces cerevisiae release factor eRF1 is methylated by the product of the YDR140w gene, J Biol Chem 280 (2005) 2439-2445.

[78] B. Polevoda, Span L., Sherman F., The yeast translation release factors Mrf1p and Sup45p (eRF1) are methylated, respectively, by the methyltransferases Mtq1p and Mtq2p, J Biol Chem 281 (2006) 2562-2571.

[79] T. Ishizawa, Nozaki Y., Ueda T., Takeuchi N., The human mitochondrial translation release factor HMRF1L is methylated in the GGQ motif by the methyltransferase HMPrmC, Biochem Biophys Res Commun 373 (2008) 99-103.

[80] A.C. Gavin, Bosche M., Krause R., Grandi P., Marzioch M., Bauer A., Schultz J., Rick J.M., Michon A.M., Cruciat C.M., Remor M., Hofert C., Schelder M., Brajenovic M., Ruffner H., Merino A., Klein K., Hudak M., Dickson D., Rudi T., Gnau V., Bauch A., Bastuck S., Huhse 
B., Leutwein C., Heurtier M.A., Copley R.R., Edelmann A., Querfurth E., Rybin V., Drewes G., Raida M., Bouwmeester T., Bork P., Seraphin B., Kuster B., Neubauer G., Superti-Furga G., Functional organization of the yeast proteome by systematic analysis of protein complexes, Nature 415 (2002) 141-147.

[81] T. Ito, Chiba T., Ozawa R., Yoshida M., Hattori M., Sakaki Y., A comprehensive twohybrid analysis to explore the yeast protein interactome, Proc Natl Acad Sci U S A 98 (2001) 4569-4574.

[82] M.H. Mazauric, Dirick L., Purushothaman S.K., Bjork G.R., Lapeyre B., Trm112p is a 15-kDa zinc finger protein essential for the activity of two tRNA and one protein methyltransferases in yeast, J Biol Chem 285 (2010) 18505-18515.

[83] S.K. Purushothaman, Bujnicki J.M., Grosjean H., Lapeyre B., Trm11p and Trm 112p are both required for the formation of 2-methylguanosine at position 10 in yeast tRNA, Mol Cell Biol 25 (2005) 4359-4370.

[84] P. Studte, Zink S., Jablonowski D., Bar C., von der Haar T., Tuite M.F., Schaffrath R., tRNA and protein methylase complexes mediate zymocin toxicity in yeast, Mol Microbiol 69 (2008) 1266-1277.

[85] S. Figaro, Scrima N., Buckingham R.H., Heurgue-Hamard V., HemK2 protein, encoded on human chromosome 21, methylates translation termination factor eRF1, FEBS Lett 582 (2008) 2352-2356.

[86] P. Liu, Nie S., Li B., Yang Z.Q., Xu Z.M., Fei J., Lin C., Zeng R., Xu G.L., Deficiency in a glutamine-specific methyltransferase for the release factor causes mouse embryonic lethality, Mol Cell Biol 30 (2010) 4245-4253.

[87] D. Liger, Mora L., Lazar N., Figaro S., Henri J., Scrima N., Buckingham R.H., van Tilbeurgh H., Heurgue-Hamard V., Graille M., Mechanism of activation of methyltransferases involved in translation by the Trm112 'hub' protein, Nucleic Acids Res 39 (2011) 6249-6259.

[88] K. Goedecke, Pignot M., Goody R.S., Scheidig A.J., Weinhold E., Structure of the N6adenine DNA methyltransferase M.TaqI in complex with DNA and a cofactor analog, Nat Struct Biol 8 (2001) 121-125.

[89] W. Gong, O'Gara M., Blumenthal R.M., Cheng X., Structure of pvu II DNA-(cytosine N4) methyltransferase, an example of domain permutation and protein fold assignment, Nucleic Acids Res 25 (1997) 2702-2715.

[90] I.R. Vetter, Wittinghofer A., The guanine nucleotide-binding switch in three dimensions, Science 294 (2001) 1299-1304.

[91] K. Das, Acton T., Chiang Y., Shih L., Arnold E., Montelione G.T., Crystal structure of RImAI: implications for understanding the 23S rRNA G745/G748-methylation at the macrolide antibiotic-binding site, Proc Natl Acad Sci U S A 101 (2004) 4041-4046. [92] M. Liu, Douthwaite S., Methylation at nucleotide G745 or G748 in 23S rRNA distinguishes Gram-negative from Gram-positive bacteria, Mol Microbiol 44 (2002) 195-204.

[93] J. Henri, Rispal D., Bayart E., van Tilbeurgh H., Seraphin B., Graille M., Structural and functional insights into Saccharomyces cerevisiae Tpa1, a putative prolylhydroxylase influencing translation termination and transcription, J Biol Chem 285 (2010) 30767-30778.

[94] G.H. Merritt, Naemi W.R., Mugnier P., Webb H.M., Tuite M.F., von der Haar T., Decoding accuracy in eRF1 mutants and its correlation with pleiotropic quantitative traits in yeast, Nucleic Acids Res 38 (2010) 5479-5492.

[95] D. Rispal, Henri J., van Tilbeurgh H., Graille M., Seraphin B., Structural and functional analysis of Nro1/Ett1: a protein involved in translation termination in S. cerevisiae and in 02-mediated gene control in S. pombe, RNA 17 (2011) 1213-1224. 
[96] M.A. Wilson, Meaux S., Parker R., van Hoof A., Genetic interactions between [PSI+] and nonstop mRNA decay affect phenotypic variation, Proc Natl Acad Sci U S A 102 (2005) 10244-10249.

[97] D. Ratel, Ravanat J.L., Charles M.P., Platet N., Breuillaud L., Lunardi J., Berger F., Wion D., Undetectable levels of N6-methyl adenine in mouse DNA: Cloning and analysis of PRED28, a gene coding for a putative mammalian DNA adenine methyltransferase, FEBS Lett 580 (2006) 3179-3184.

[98] D.S. Nie, Liu Y.B., Lu G.X., Cloning and primarily function study of two novel putative N5-glutamine methyltransferase (Hemk) splice variants from mouse stem cells, Mol Biol Rep 36 (2009) 2221-2228.

[99] E.M. Kolonko, Albaugh B.N., Lindner S.E., Chen Y., Satyshur K.A., Arnold K.M., Kaufman P.D., Keck J.L., Denu J.M., Catalytic activation of histone acetyltransferase Rtt109 by a histone chaperone, Proc Natl Acad Sci U S A 107 (2010) 20275-20280.

[100] A. Alexandrov, Martzen M.R., Phizicky E.M., Two proteins that form a complex are required for 7-methylguanosine modification of yeast tRNA, RNA 8 (2002) 1253-1266.

[101] J. Anderson, Phan L., Hinnebusch A.G., The Gcd10p/Gcd14p complex is the essential two-subunit tRNA(1-methyladenosine) methyltransferase of Saccharomyces cerevisiae, Proc Natl Acad Sci U S A 97 (2000) 5173-5178.

[102] T. Gonatopoulos-Pournatzis, Dunn S., Bounds R., Cowling V.H., RAM/Fam103a1 Is Required for mRNA Cap Methylation, Mol Cell 44 (2011) 585-596.

[103] X. Mao, Shuman S., Intrinsic RNA (guanine-7) methyltransferase activity of the vaccinia virus capping enzyme D1 subunit is stimulated by the D12 subunit.

Identification of amino acid residues in the D1 protein required for subunit association and methyl group transfer, J Biol Chem 269 (1994) 24472-24479.

[104] J. Armengaud, Urbonavicius J., Fernandez B., Chaussinand G., Bujnicki J.M., Grosjean H., N2-methylation of guanosine at position 10 in tRNA is catalyzed by a THUMP domain-containing, S-adenosylmethionine-dependent methyltransferase, conserved in Archaea and Eukaryota, J Biol Chem 279 (2004) 37142-37152.

[105] D. Fu, Brophy J.A., Chan C.T., Atmore K.A., Begley U., Paules R.S., Dedon P.C., Begley T.J., Samson L.D., Human AlkB homolog ABH8 Is a tRNA methyltransferase required for wobble uridine modification and DNA damage survival, Mol Cell Biol 30 (2010) 2449-2459.

[106] H.R. Kalhor, Clarke S., Novel methyltransferase for modified uridine residues at the wobble position of tRNA, Mol Cell Biol 23 (2003) 9283-9292.

[107] V. Leihne, Kirpekar F., Vagbo C.B., van den Born E., Krokan H.E., Grini P.E., Meza T.J., Falnes P.O., Roles of Trm9- and ALKBH8-like proteins in the formation of modified wobble uridines in Arabidopsis tRNA, Nucleic Acids Res (2011).

[108] L. Songe-Moller, van den Born E., Leihne V., Vagbo C.B., Kristoffersen T., Krokan H.E., Kirpekar F., Falnes P.O., Klungland A., Mammalian ALKBH8 possesses tRNA methyltransferase activity required for the biogenesis of multiple wobble uridine modifications implicated in translational decoding, Mol Cell Biol 30 (2010) 1814-1827. [109] U. Begley, Dyavaiah M., Patil A., Rooney J.P., DiRenzo D., Young C.M., Conklin D.S., Zitomer R.S., Begley T.J., Trm9-catalyzed tRNA modifications link translation to the DNA damage response, Mol Cell 28 (2007) 860-870.

[110] M.J. Johansson, Esberg A., Huang B., Bjork G.R., Bystrom A.S., Eukaryotic wobble uridine modifications promote a functionally redundant decoding system, Mol Cell Biol 28 (2008) 3301-3312.

[111] D. Jablonowski, Zink S., Mehlgarten C., Daum G., Schaffrath R., tRNAGlu wobble uridine methylation by Trm9 identifies Elongator's key role for zymocin-induced cell death in yeast, Mol Microbiol 59 (2006) 677-688. 
[112] J.P. Derrick, Wigley D.B., Crystal structure of a streptococcal protein G domain bound to an Fab fragment, Nature 359 (1992) 752-754.

[113] M. Graille, Stura E.A., Housden N.G., Beckingham J.A., Bottomley S.P., Beale D., Taussig M.J., Sutton B.J., Gore M.G., Charbonnier J., Complex between Peptostreptococcus magnus Protein L and a Human Antibody Reveals Structural Convergence in the Interaction Modes of Fab Binding Proteins, Structure (Camb) 9 (2001) 679-687. [114] S. Ghaemmaghami, Huh W.K., Bower K., Howson R.W., Belle A., Dephoure N., O'Shea E.K., Weissman J.S., Global analysis of protein expression in yeast, Nature 425 (2003) 737-741.

[115] C. Chen, Huang B., Anderson J.T., Bystrom A.S., Unexpected accumulation of ncm(5)U and ncm(5)S(2) (U) in a trm9 mutant suggests an additional step in the synthesis of mcm(5)U and mcm(5)S(2)U, PLoS One 6 (2011) e20783.

[116] Z. Hu, Qin Z., Wang M., Xu C., Feng G., Liu J., Meng Z., Hu Y., The Arabidopsis SMO2, a homologue of yeast TRM112, modulates progression of cell division during organ growth, Plant J 61 (2010) 600-610.

\section{Legends to figures.}

Figure 1: Class I release factors.

A. Structure of the closed conformation of bacterial RF2 protein. The domains I, II, III and IV are coloured in pink, orange, red and yellow, respectively. The "SPF" motif, which interacts with the stop codon and the GGQ motif are depicted as sticks and balls, respectively. PDB code used to generate this figure: 1GQE [4]. With the exception of Fig.3C, all figures were generated using the PYMOL software (http:// www.pymol.org).

B. Structure of the bacterial RF2 bound to ribosomes. The same colour code as in panel A is used. Inset: Representation of the RF2 ribosomal termination complex. The $30 \mathrm{~S}$ and 50S subunits are coloured in grey and wheat, respectively. The P-site and Esite tRNAs are coloured in light and dark green, respectively. The mRNA is coloured in purple. PDB codes used to generate this figure: 2X9R and 2X9S [68].

C. Structure of human eRF1. The N-terminal, central and C-terminal domains are in orange, red and purple, respectively. The "NIKS" motif from the N-terminal domain and the GGQ motif are shown as sticks. PDB code used to generate this figure: 1DT9 [3].

Figure 2: Methylation of bacterial RFs. 
A. Structure of E. coli PrmC. The N-terminal and C-terminal domains are coloured in blue and green. The linker connecting both domains is in light blue. The S-AdenosylL-Homocysteine (SAH) ligand is shown as grey sticks. PDB code used to generate this figure: $1 \mathrm{NV} 9$ [61].

B. Structure of the PrmC-RF1 complex from E. coli. The PrmC and RF1 are represented using the same colour codes as panels A and Fig.1A, respectively. The RF1 GGQ motif is shown as balls and sticks. The "PAT" motif contacting the stop codon and the SAH molecule are shown in sticks. PDB code used to generate this figure: 2B3T [62].

C. Detailed representation of the GGQ binding mode into PrmC active site. The PrmC MTase domain is shown in green. The RF1 containing the GGQ motif is shown in red and the GGQ motif is highlighted in brown sticks. The hydrogen bonding network coordinating the Gln side chain into the PrmC active site is depicted by black dashed lines. The methyl group (grey sphere) to be transferred from SAM to the Gln side chain has been modelled by substituting SAH by SAM.

D. Modelling of the GGQ methylation into the peptidyl transferase center. For clarity, only bases contacting the GGQ motif are depicted. The RF2 loop harbouring the GGQ motif is coloured in purple. The P-site tRNA analog is shown in green. PDB codes used to generate this figure: $2 \mathrm{X} 9 \mathrm{R}$ and $2 \mathrm{X} 9 \mathrm{~S}$ [68].

\section{Figure 3: Eukaryotic RF methyltransferase.}

A. Structure of the Mtq2-Trm112 complex from E. cuniculi. The SAM molecule bound to Mtq2 is shown as grey sticks. A cyan sphere depicts the zinc atom bound to Trm112 and the 4 cystein residues coordinating this zinc are shown as sticks. PDB code used to generate this figure: 3Q87 [87].

B. Comparison of Mtq2 and PrmC active sites. PDB code used to generate this figure: $3 \mathrm{Q} 87$ and 2B3T $[62,87]$.

C. The Trm112 protein is an activator of 3 methyltransferases modifying translation factors. The tRNA positions modified by Trm9-Trm112 and Trm11-Trm112 are coloured in blue and magenta, respectively. 

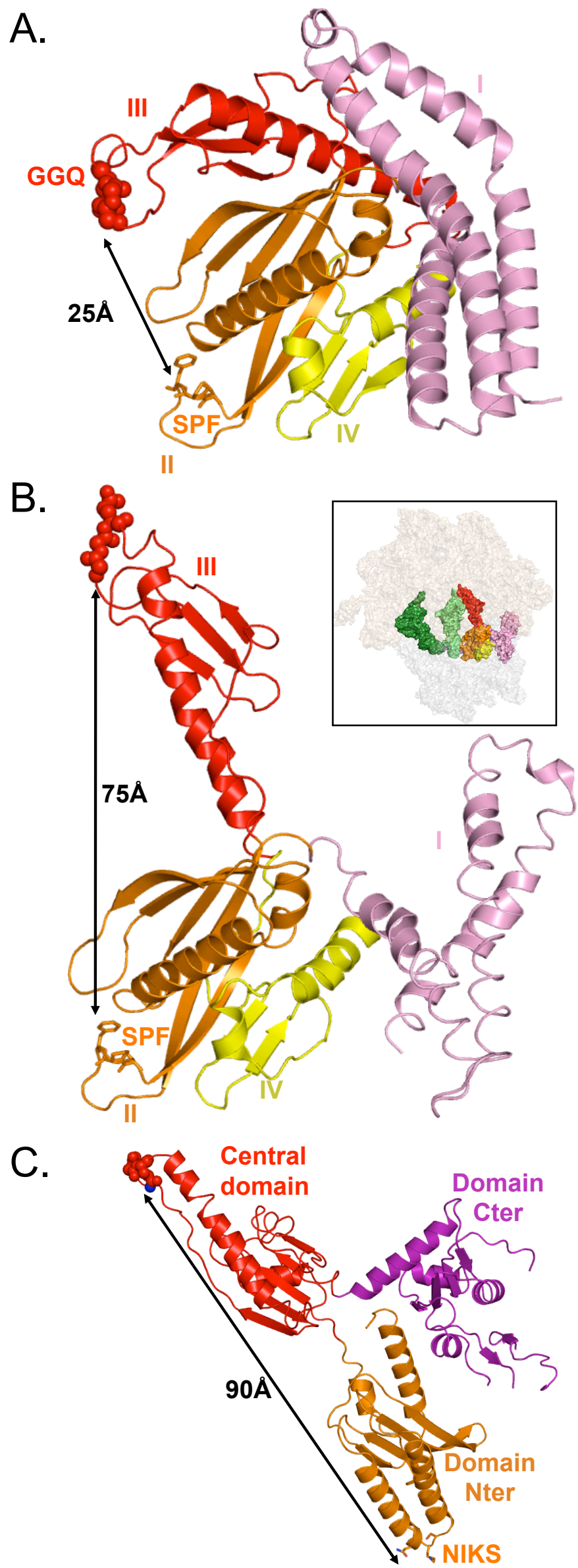

Figure 1 
A.

B.
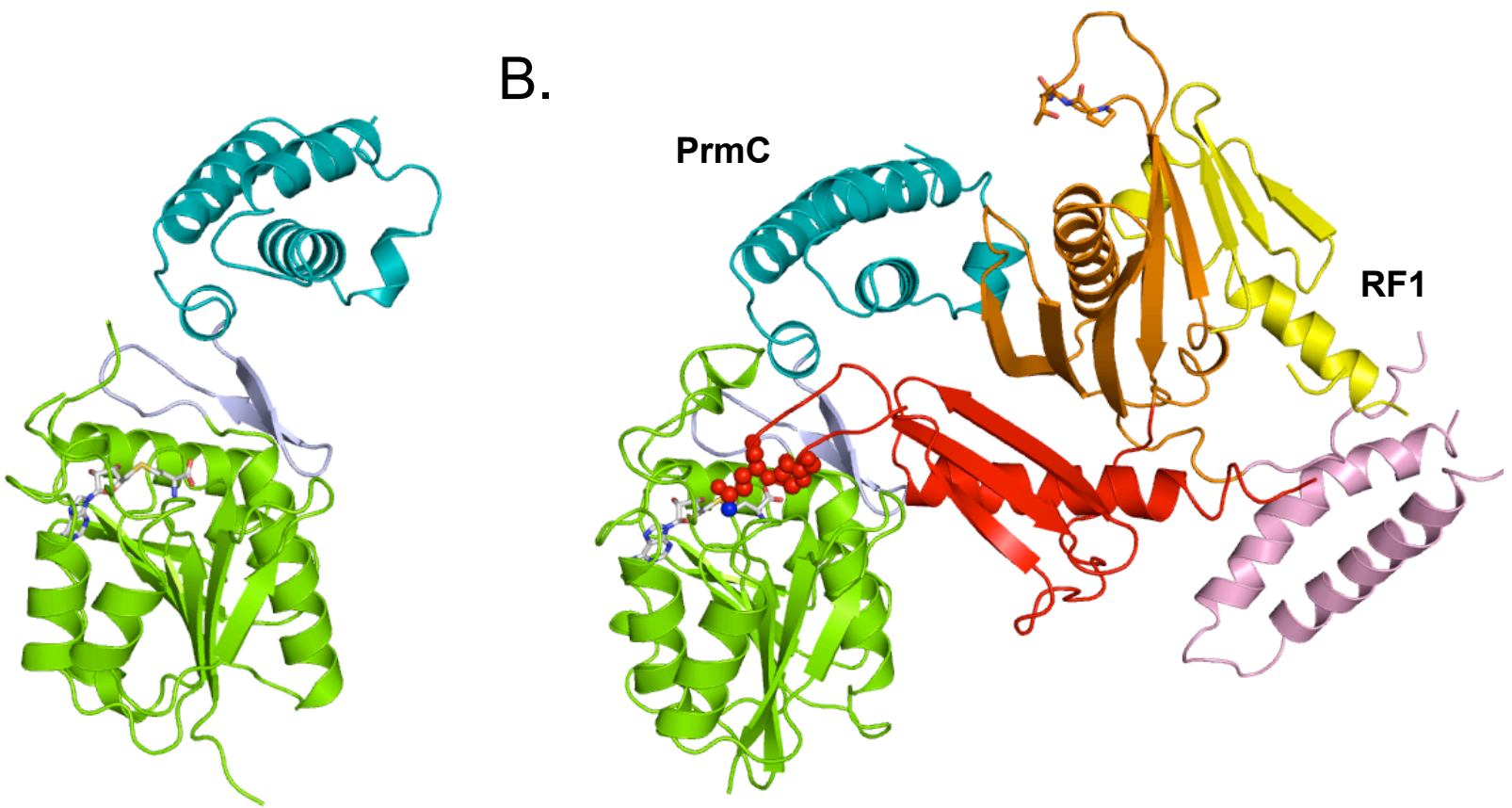

C.

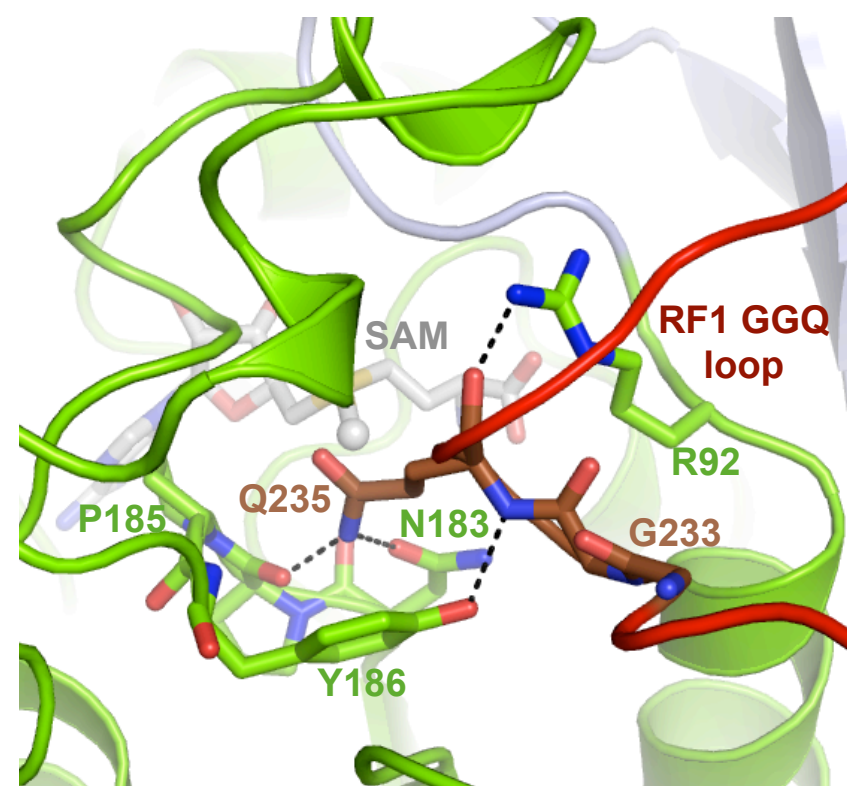

D.

P-site tRNA

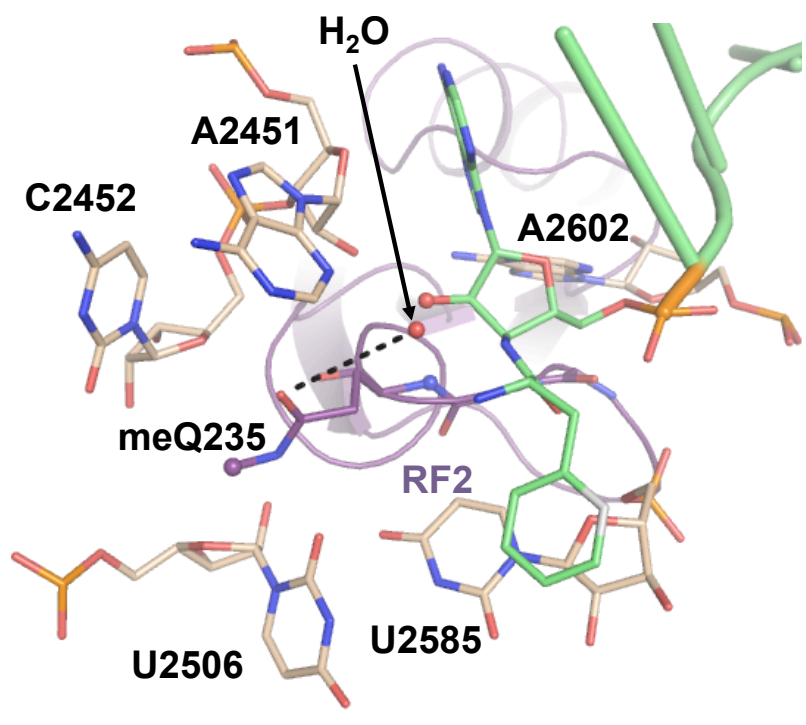

Figure 2 
A.

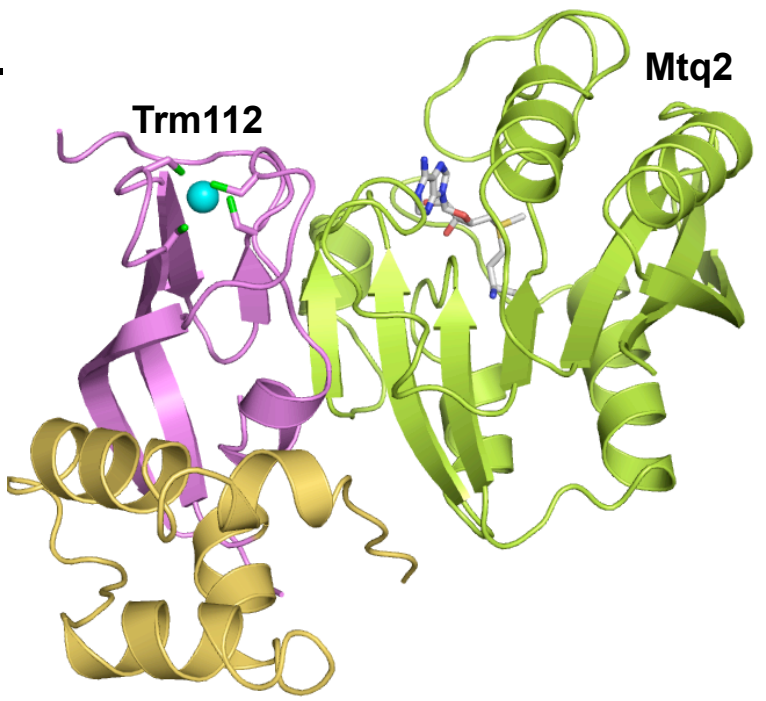

B.

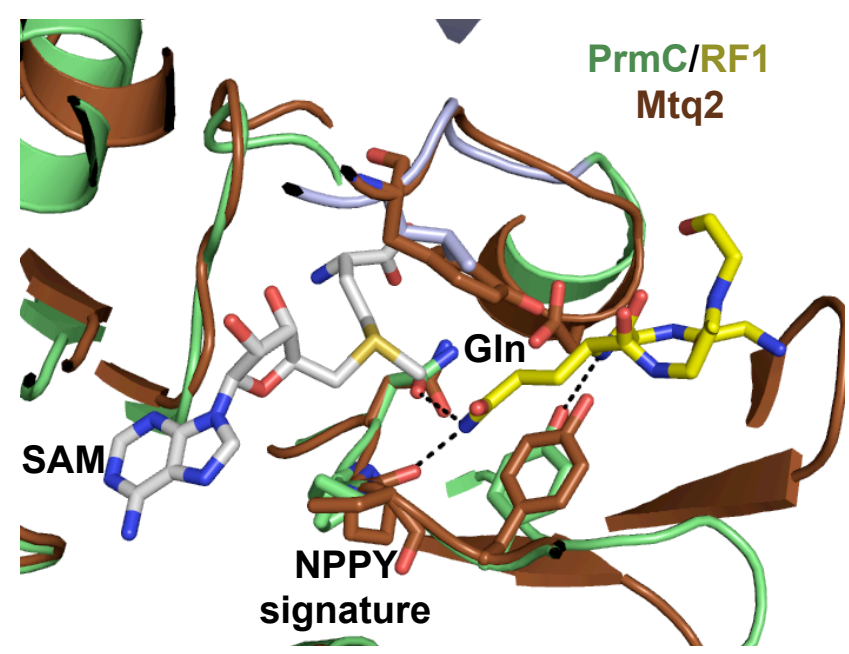

C.

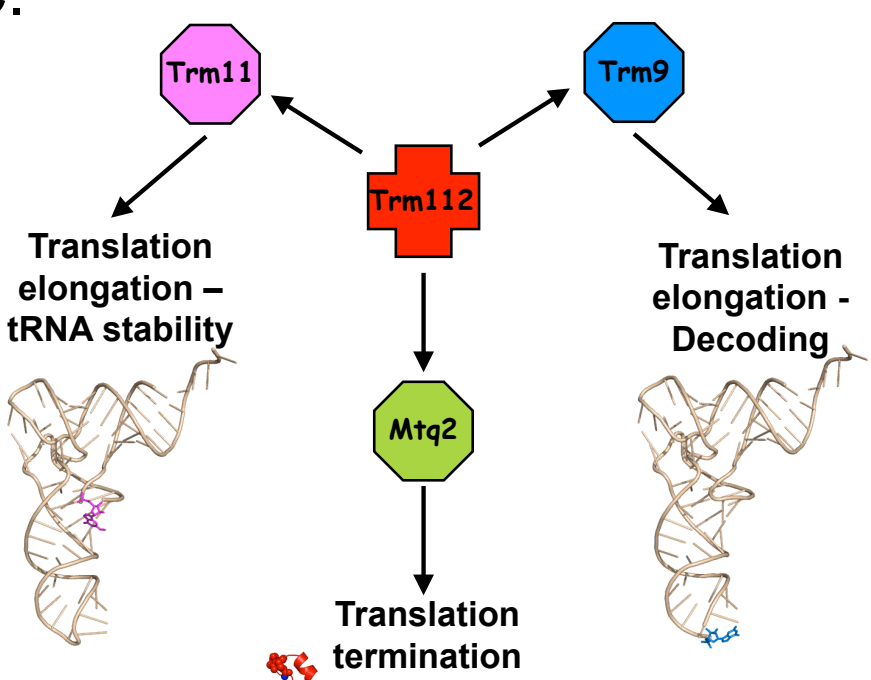
termination 
Table 1: Methylated RF and MTases in different organisms

\begin{tabular}{|l|l|l|}
\hline Organisms & Substrate & Methyltransferase \\
\hline E. coli & RF1, RF2 & PrmC \\
\hline S. cerevisiae & Mrf1 (mitochondrial RF) & Mtq1 \\
\hline & eRF1 + eRF3 + GTP & Mtq2 +Trm112 \\
\hline H. sapiens & HMRF1L (mitochondrial RF) & HMPrmC \\
\hline M. musculus & eRF1 + eRF3 + GTP & HemK2 $\alpha+\mathrm{hTrm112}$ \\
\hline & & PRED28 $\alpha / \mathrm{N} 6 \mathrm{amt} 1+\mathrm{mTrm} 112$ \\
\hline
\end{tabular}

